\title{
Tri-axial Shear Test of Different Damage Remolded Expansive Soil
}

\author{
Liu Yongsheng*,1, Wang Shiji ${ }^{2}$ and Dong Xinyu ${ }^{1}$
}

${ }^{1}$ School of Civil Engineering and Architecture, East China Jiaotong University, Nanchang 330013, China

${ }^{2}$ College of Engineering and Technology, Southwest University, Chongqing 400716, China

\begin{abstract}
The deformation and strength characteristics of damaged remolded expansive soil are studied by the tri-axial tests of different bore diameter damaged expansive soil. The results show that the area and location of cylindrical bores have significant effect on the mechanical and deformation characteristics of the soil. Little damage can improve the shear bearing capacity of the specimen; but when the damage is large, the bearing capacity of the specimen is weakened with the increasing damage. Under the same shearing conditions, partial strain is less than 7\%; the specimens with same damage area and different damage locations have the same force form; while if the partial strain exceeds by $7 \%$ in the same damage area, the bores are closer to the center of the specimen and the shear strength is smaller.
\end{abstract}

Keywords: Damage area, damage locations, expansive soil, tri-axial shear test, remolded expansive soil.

\section{INTRODUCTION}

Expansive soil is a kind of geological body having full crack and significant swell-shrink. Expansive soil develops various kinds of cracks which provides it with the characteristic of multi-fissure. These cracks are produced by the actions of various geologic forces such as sedimentation, compaction, weathering, rain erosion and swell effect in the formation process of expansive soil [1]. The research on the expansive soil's micro-structure shows that expansive soil also has a certain structure. Under the action of load or environment, the irreversible changes occur in micro structure and this reduces the mechanical performance of expansive soil. This is called the original damage [2]. Crack propagation is dependent on the process of damage development but mutually influences the interaction. So many dispersed micro cracks are usually considered as local uniform field, and then an appropriate state variable is described to study the overall effect of the crack development and the variable is called the damage variable.

There have been a number of researches on the expansive soil at home and abroad. The expansive soil is mainly concentrated in its discrimination and classification, strength properties and fracture studies, and in the micro tests, there have been many research achievements by CT technology. Dang fangning $[3,4]$ defined the concepts of integrity and damage regarding rock and soil medium using the set theory and measured theory knowledge, and studied the position and damage criterion on the basis of CT number.

The research team of Chen Zhenhan [5-7] conducted indepth research for unsaturated soil and special soil, and obtained the systematic creative achievements. They

"Address correspondence to this author at the School of Civil Engineering and Architecture, East China Jiaotong University, Nanchang, Jiangxi, China 330013; Tel: 85-971-87046707; Fax: 85-971-87046720;

E-mail:yshliu07@126.com revealed many important mechanical properties of the unsaturated soil and special soil regarding moisture movement rule and deformation, strength, yield, water change, saturated yielding, wet swelling, mini-structure evolution, temperature effect and so on, constructed the axiomatic system of rock and soil mechanics and a variety of combimation stress state variables of unsaturated soil, put forward the effective stress theoretical formula of anisotropic porous media and unsaturated soil, set up the constitutive model spectrum (including the models of nonlinearity, elastic-plastic, structural damage and thermal coupling) of the unsaturated soil, the collapsible loess and the expansive soil and the characteristic curve model spectrum considering the influence of density, net mean stress and deviatoric stress of generalized soil-water, created the three-dimensionl consolidation theory and its model spectrum of unsaturated soil, developed a series of softwares, gained the analytical solution for one-dimensional consolidation problem and numercal solution for two-dimensional one, and then formed a complete theoretical system.

Wang Shiji [8-10] evaluated the effect of hole damage on the mechanical properties such as strength, deformation and stability, quantitatively studying the effect of hole structure damage evolution rule. The research showed that the volume of damage sample shear contraction in the process of triaxial shear tests and the damage hole diameter tended to be monotonous under the condition of appropriate moisture content moderate small damage soil sample tri-axial shear strength by $25 \%$ and volume strain also relatively decreased. (AUTHOR: The highlighted is vague and must be rephrased) And the shear strength of the specimens with the same damage area was almost the same, but the volume strain did not have the same rule.

Based on the existing research results, the tri-axial shear tests of bore damage specimens which controlled confining pressure and suction to constant were conducted, andthe effects of hole damage on bearing capacity, deviatoric stress, 
volumetric strain and deviatoric strain were studied and the evolution rule was analyzed.

\section{MATERIALS AND TEST SCHEME}

\subsection{Preparations for the Specimens}

The undisturbed expansive soil was crushed and dried initially, and then according to the test requirements of dry density and moisture content, water was distributed and compacted hierarchically. The specimens' diameter and height were $3.91 \mathrm{~cm}$ and $8 \mathrm{~cm}$, with an initial volume of $96 \mathrm{~cm}^{3}$. Before the specimens were taken out from the sleeve, different diameter cylindrical holes were made having different diameters of hollow metal bar. The specimens are shown in Fig. (1). The specimens labelled as \#1 had no hole ones, the $\# 2$ were the ones with $3 \mathrm{~mm}$ middle-hole, the $\# 3$ were the ones with $6 \mathrm{~mm}$ middle-hole, the \#4 were the ones having $6 \mathrm{~mm}$ ccentric-hole and the $\# 5$ were the ones with $4 \times$ $3 \mathrm{~mm}$ eccentric-hole. After molding, the specimens were cured in a stand-by moisture tank. The physical indicators of the specimens are shown in Table $\mathbf{1}$.

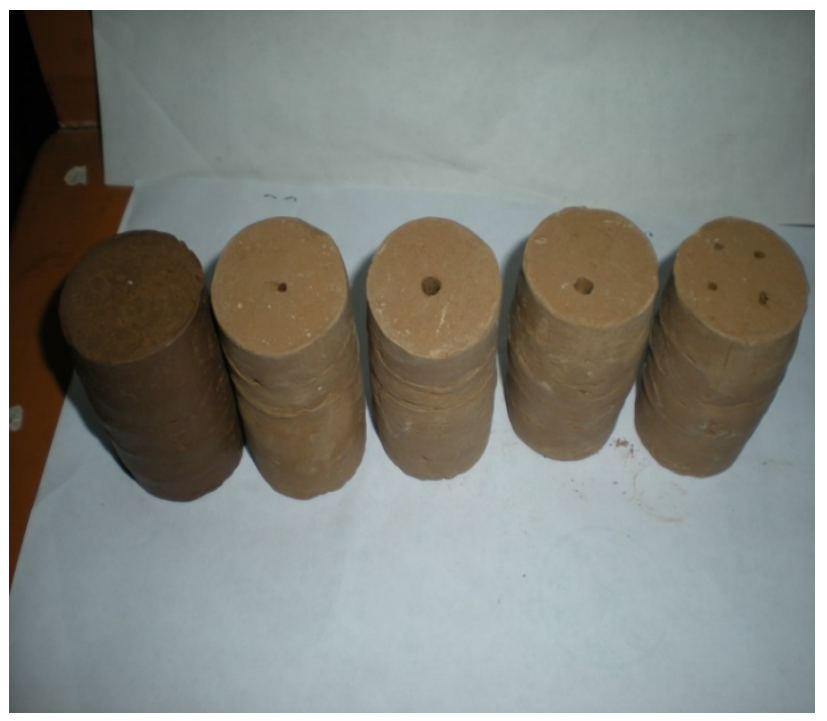

Fig. (1). Specimens.

Table 1. Original states of specimens.

\begin{tabular}{|c|c|c|c|c|}
\hline $\begin{array}{c}\text { Relative } \\
\text { density } \boldsymbol{p}_{\mathbf{s}}\end{array}$ & $\begin{array}{c}\text { Dry density/ } \\
\left(\mathbf{g} / \mathbf{c m}^{\mathbf{3}}\right)\end{array}$ & $\begin{array}{c}\text { Moisture } \\
\text { content } \mathbf{w} / \\
\%\end{array}$ & $\begin{array}{c}\text { Saturation } \\
\mathbf{S r} / \%\end{array}$ & $\begin{array}{c}\text { Void } \\
\text { ratio } e\end{array}$ \\
\hline \hline 2.73 & 1.55 & 24.0 & 86.07 & 0.76 \\
\hline
\end{tabular}

\subsection{Experiment Scheme}

The experimental device is the FALSY30-1 stress and strain controlling tri-axial apparatus of unsaturated soil, (AUTHOR: The highlighted text is vague and must be rephrased) shown in Fig. (2). Before the test, the specimen was put in the double pressure chamber of the apparatus for consolidation under certain pressure, and then the tests of three tri-axial shear after deformation and drainage stability were conducted having the shear rate as $0.0167 \mathrm{~mm} / \mathrm{min}$. Because the displacement was very small, the volume strain was taken as a standard to judge the stability. The volume change was observed to be not more than $0.0063 \mathrm{~cm}^{3}$ every two hours, while drainage did not exceed $0.012 \mathrm{~cm}^{3}$ per hour. The net confining pressure was $100 \mathrm{kPa}$ and the suction was $50 \mathrm{kPa}$.

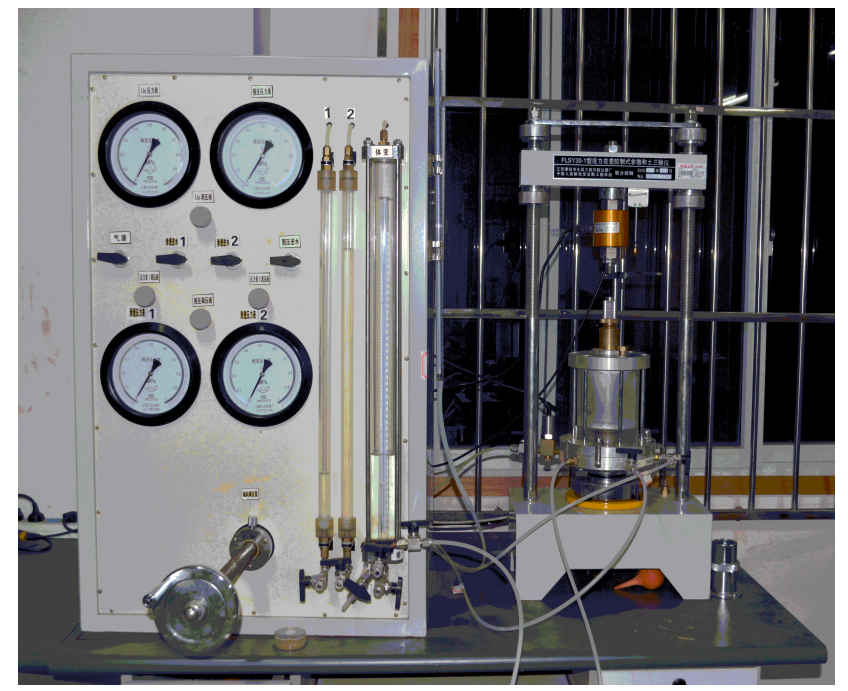

Fig.(2). FALSY30-1 test apparatus.

\section{STRESS PARAMETERS}

This paper used two stress state variables: net total stress tensor $\left(s_{i j}-u_{a} d_{i j}\right)$ and suction tensor $\left(u_{a}-u_{w}\right)$, in the formula: $s_{i j}$ - the total stress tensor, $u_{a}$ - porosity gas pressure, $u_{w}$-pore water pressure, $d_{i j}$ - Kronecker mark. For expressing conveniently, the following notations were used to describe the tri-axial stress state:

$$
\begin{aligned}
p & =\frac{s_{1}+s_{2}+s_{3}}{3}-u_{a} \\
q & =s_{1}-s_{3} \\
s & =u_{a}-u_{w}
\end{aligned}
$$

Here: $p, q, s$ are net mean stress, deviatoric stress and suction respectively; $s_{1}, s_{2}, s_{3}$ are the three principal stresses having unit : $\mathrm{kPa}$. The volume strain $e_{v}$ and deviatoric strain $e_{s}$ are defined as follows:

$$
\begin{aligned}
& e_{v}=\frac{\mathrm{D} V}{V_{0}}=e_{1}+2 e_{3} \\
& e_{s}=\frac{2}{3}\left(e_{1}-e_{3}\right)
\end{aligned}
$$

Here: $\mathrm{D} V$ is the volume change of the sample, $V_{0}$ is the initial volume, $e_{1}$ is the major principal strain and $e_{3}$ is the principal strain.

\section{EXPERIMENTAL RESULTS AND ANALYSES}

\subsection{Experimental Results}

The tri-axial shear tests of five different damaged specimens were conducted and the curves between axial 
strain and load were obtained as shown in Fig. (3). From Fig. (3), it can be found that at the early stage of the tests (axial strain varied during $0 \% \sim 2 \%$ ), the load increased sharply with the increase in axial strain, and the specimen showed obvious change. With the increase in the load, the curves of the specimen were observed to be gentle. The elastic limit of the $3 \mathrm{~mm}$ hole specimen was the largest; those of $4 \times 3 \mathrm{~mm}$ hole and $6 \mathrm{~mm}$ hole specimens were taken in the second place, and it was the smallest of the no hole specimen.

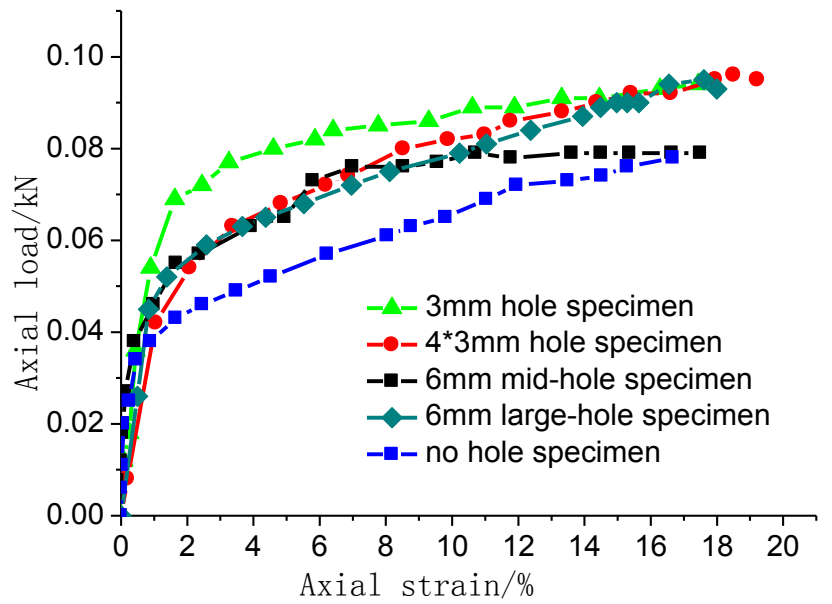

Fig. (3). Curves of the axial strain and load.

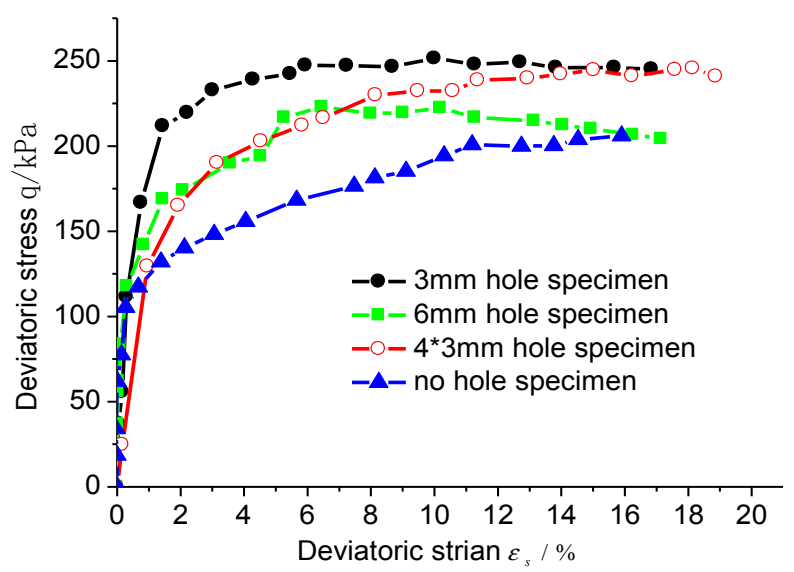

Fig. (4). Curves of deviatoric stress-strain.

\subsection{The Influence of Damage Degree}

The relationship curves between deviatoric stress and deviatoric strain of the different damage specimens are shown in Fig. (4). According to Fig. (4), the deviatoric stress increased with the increasing deviatoric strain. The deviator shear stress of the no hole specimen was the minimum, $3 \mathrm{~mm}$ hole specimen was the strongest, and $6 \mathrm{~mm}$ hole specimen's and $4 \times 3 \mathrm{~mm}$ hole specimen's were moderate. It can be concluded that appropriate damage could increase the deviator stress of the specimen, improving the ability of resistance deformation and failure. But it is not favorable if the damage is too large. Comparing the $6 \mathrm{~mm}$ hole specimen curve and the $4 \times 3 \mathrm{~mm}$ hole, it could be found that the deviatoric stress values were basically the same when the strain increased from $0 \%$ to $7 \%$, showing that damage had a little effect on the deviatoric stress if deviatoric strain was small. The curve showing obvious bifurcation indicated that the deviatoric strain increased by
$7 \%$ and the deviatoric stress values of $6 \mathrm{~mm}$ hole specimens were much smaller than $4 \times 3 \mathrm{~mm}$ hole specimen. This showed that the damage size and its location affected the shear stress, and the greater the damage and the closer it is to the middle of the specimen, the smaller the specimen's failure stress.

The curves of the relation between volume strain and spherical stress are shown in Fig. (5). It can be inferred form Fig. (5) that the volume strain increased with the increase in spherical stress at the early shear stage, and the increasing degree was the same. When the volume strain reached $0.4 \%$, the spherical stresses of different specimens began to indicate some difference. The spherical stress of no hole specimen was minimum, that of the $3 \mathrm{~mm}$ hole specimen was the strongest, and the $4 \times 6 \mathrm{~mm}$ hole specimen's was moderate. This also indicated that to produce the same volume deformation, the $3 \mathrm{~mm}$ hole specimen needs maximum net water pressure, and the no hole specimen needs minimum net water pressure. It showed that appropriate damage can enhance the ability of resistance to deformation of reshaped expansive soil. In addition, the study found that when the spherical stress increases to a certain extent, dilatancy phenomenon appears in the damaged specimen, and the greater the damage degree, the more obvious the phenomenon .

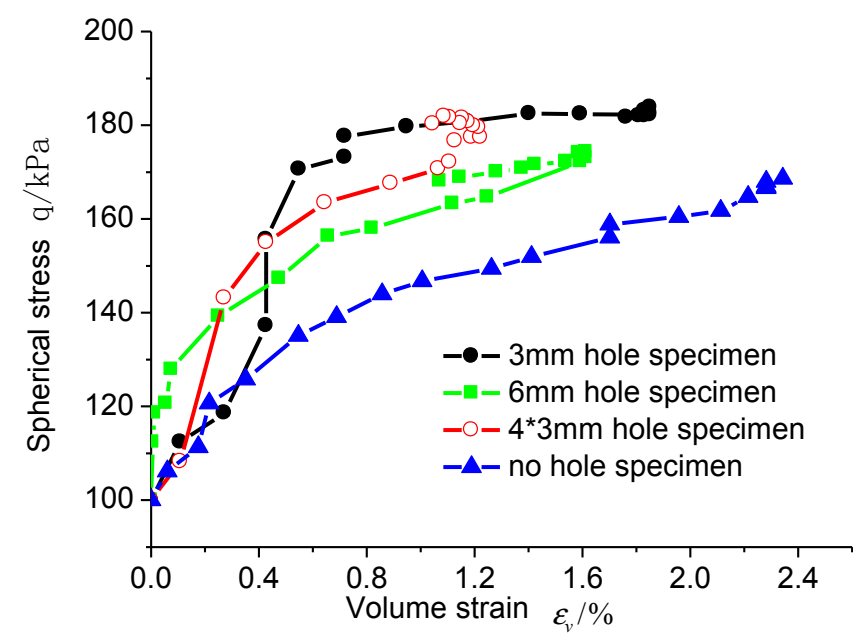

Fig. (5). Curves of spherical stress-volume strain.

\subsection{The Influence of Damage Location}

The shear tests of the specimens of $6 \mathrm{~mm}$ center-hole and $6 \mathrm{~mm}$ side-hole were carried out. The relationship curves between deviatoric stress and spherical stress and strain of the specimen are shown in Fig. (6).

From Fig. (6a), it can be known that when deviatoric strain was less than $10 \%$, the deviatoric stresses of $6 \mathrm{~mm}$ center-hole and side-hole specimens with the same damage area were the same. When deviatoric strain was more than $10 \%$, the center-hole specimen's deviatoric stress was much lesser than the side-hole's. From Fig. (6b), when the volume strain was less than $0.7 \%$, two kinds of specimens with different damage locations had the same spherical stressvolume strain relationship. When the volume strain was more than $0.7 \%$, the center-hole specimen's spherical stress was less than side-hole's under the same volume strain. The 
phenomena indicated that with different damage locations, the specimens' stress response relationship was not the same even under the same damage. When the damage location was at the center of the specimen, the effect caused by damage was more obvious and the ability to resist the deformation was weaker.

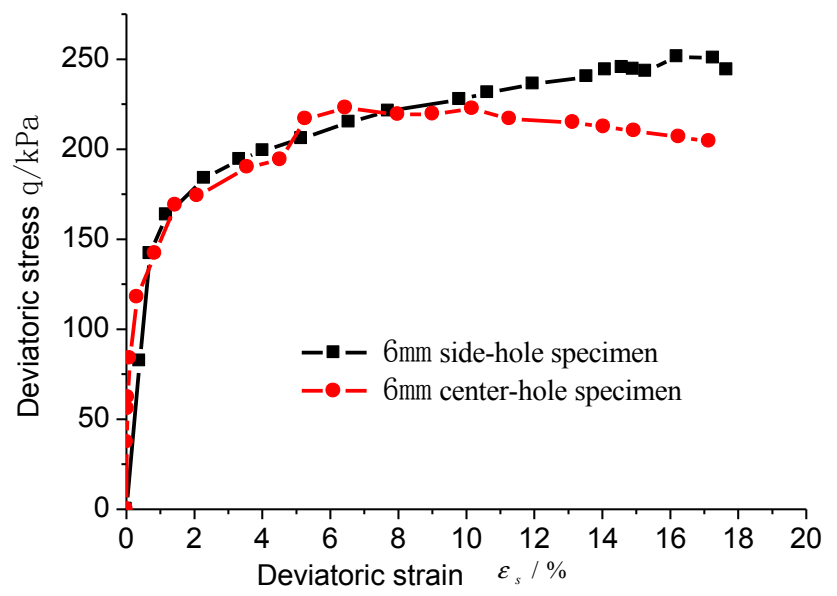

(a) curves of deviatoric stress- strain

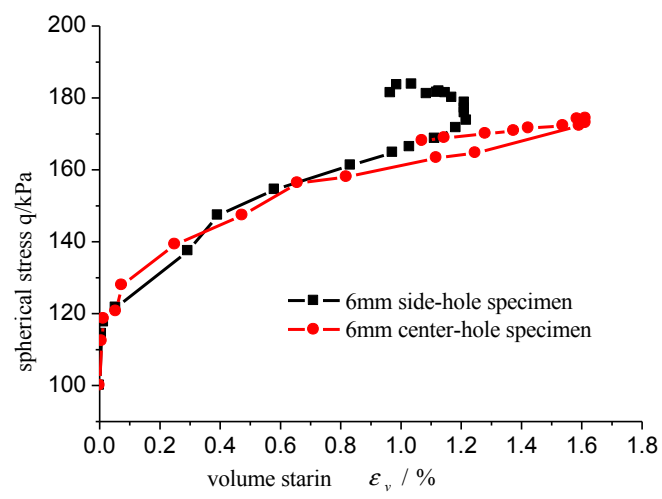

(b) curves of the spherical stress-volume strain

Fig. (6). Characteristics comparison of center-hole specimens and side-hole specimens.

\section{CONCLUSION}

The strength and deformation characteristics of remolded expansive soil with different damages were studied in this paper by conducting the tri-axial shear tests. The results are as follows:

(1) The spherical stress and deviatoric stress of hole specimens are higher than those of no hole specimens under the same conditions, which illustrates that the appropriate damage is helpful to improve the ability to resist shear deformation of remolded expansive soil.

(2) Under the same shear conditions, the damage quantity and damage location affect the shear failure stress. The closer the hole damage to the middle of the specimen, the smaller the specimen's failure stress.

(3) Under the same shear conditions, the same damage area of specimen damage location affects the volume change. And the nearer the hole to the edge of the sample, the greater the spherical stress reaches the maximum value of volume strain. At the same time, the whole sample volume can be compensated in the damage holes in the shearing process.

\section{CONFLICT OF INTEREST}

The authors confirm that this article content has no conflict of interest.

\section{ACKNOWLEDGEMENTS}

This work is supported by the Chinese Natural Science Foundation (51274101) and JiangXi Science and technology support program (20121BBG70064).

\section{REFERENCES}

[1] T. Liu, "Problems of Expansive Soil in Construction," Beijing, pp. 56-62, 1997.

[2] S. Yu, X. Feng, "Damage Mechanics," Beijing, pp. 33-45, 1997.

[3] F. Dang, "Damage-fracture evolution theory of rock and soil (I): damage fracture space," Rock and Soil Mechanics, vol. 26, pp. 513$519,2005$.

[4] F. Dang, "Damage-fracture evolution theory of rock and soil (II): physical state indexes and divisional damage-fracture theory," Rock and Soil Mechanics, vol. 26, pp. 673-679, 2005.

[5] Z. Chen, "On basic theories of unsaturated soils and special soils," Chinese Journal of Geotechnical Engineering, vol. 36, pp. 201272, 2014.

[6] Z. Lu, "Elastoplastic Damage Constitutive Model of Unsaturated Expansive Soil and its Application in Slope Field Coupling Analysis," Chongqing: Logistic Engineering University of PLA, 2001.

[7] Z. Lu, Z. Chen, and Y. Pu, "Quantitative analysis on damage evolution of intact expansive soil during triaxial shearing test," Rock and Soil Mechanics, vol. 23, pp. 1428-1432, 2004.

[8] S. Wang, Z. Chen, and X. Li, "Experimental study on pore-damage evolution of remolded soil," Transactions of the Chinese Society of Agricultural Engineering, vol. 33, pp. 128-132, 2011.

[9] S. Wang, S. Sun, and Z. Chen, "Triaxial shear test of pore-damaged remolded Expansive soil," Journal of Southwest University(Natural Science Edition), vol. 33, pp. 128-132, 2011.

[10] S. Wang, Y. Han, and X. Li, "Study of strength and deformation of cylindrical hole damaged expansive soil by CT-triaxial test," Rock and Soil Mechanics, vol. 34, pp. 2763-2768, 2014. 